\title{
Infant formula supplemented with low protein and high carbohydrate alters the intestinal microbiota in neonatal SD rats
}

Wenguang Fan ${ }^{1,2}$, Yaru Tang ${ }^{1}$, Yi Qu ${ }^{2}$, Fengbo Cao ${ }^{1}$ and Guicheng Huo ${ }^{1 *}$

\begin{abstract}
Background: Infant microbiota is influenced by numerous factors, such as delivery mode, environment, prematurity and diet (breast milk or formula) and last but not least, the diet composition. In the diet composition, protein and carbohydrate are very important for the growth of microbiota, many infant fomulas (different ratio protein/ carbohydrate) can regulate the development of gut microbiota by different metabolism. The effect of low-protein, high-carbohydrate infant formula on the establishment of microbiota remains unclear, and the effect of human breast milk on the gut microbiota of the rats has also not been reported.
\end{abstract}

Results: In a $7 \mathrm{~d}$ intervention, a total of 36 neonatal SD rats ( $14 \mathrm{~d}$ old) were randomly assigned to the following groups: (1) breast-fed group (A group); (2) low-protein, high-carbohydrate infant formula-fed group (B group); (3) human breast milk-fed group (C group). After 7 days, we selected 6 rats at random from each group to study. Microbial composition in the contents of the large intestines was analysed by Miseq Sequencing. Significantly different $(p<0.05)$ microbial colonisation patterns were observed in the large intestines of breast-fed group from low-protein, high-carbohydrate infant formula-fed and human breast milk-fed rats, but the microbiota of low-protein, high-carbohydrate infant formula-fed group and human breast milk-fed group have high similarity. At the phylum level, the absolute quantity of Bacteroidetes, Firmicutes and Proteobacteria $(p<0.001)$ significantly differentiated in breast-fed group from low- protein, high- carbohydrate infant formula-fed and human breast milk-fed groups. Lachnospiraceae, Bacteroidaceae, Porphyromonadaceae and Prevotellaceae were the 4 top families in breast-fed group, but the top 4 families in low-protein, high- carbohydrate infant formula-fed and human breast milk-fed groups were the same, which were Bacteroidaceae, Enterobacteriaceae, Porphyromonadaceae and Lachnospiraceae. At the genus level, Bacteroides was the most abundant division, their OTUS abundance in three groups was 14.91\%, 35.94\%, 43.24\% respectively.

Conclusions: This study showed that infant formula closer resembling human milk was more different than rats' breast milk and led to a microbiota profile similar to that for human breast milk-fed neonates. The finding could support a new thinking to develop infant formulas, and provide much more details than what is known previously.

Keywords: SD rats, Breast-fed, Low-protein, High-carbohydrate infant formula-fed, Human breast milk-fed, Microbiota

\section{Background}

The gastrointestinal tract is a complex ecosystem that always harbors a diverse bacterial community [1]. During the evolution of both the gut microbiota and the host, the gut microbial community has become an integral component of the host and may affect the host biology [2,3], and it plays a crucial role in health since it is involved in

\footnotetext{
* Correspondence: gchuo58@163.com

'Key Laboratory of Dairy Science, Ministry of Education, Northeast

Agricultural University, Harbin 150030, China

Full list of author information is available at the end of the article
}

nutrition, pathogenesis, and immunology [4]. Microbial imbalance has been linked to several functional gut disorders. Among its many important functions, the gut microbiota can convert nutritional ingredient into microbial biomass and fermentation end products that can be utilized by the host $[5,6]$.

Infancy is a critical period of colonization of the intestinal microbiota, which affects the adult intestinal microbiota and the future health [7]. The establishment of infant intestinal microbiota is influenced by many factors, the feeding mode does have a crucial impact. Breast-feeding is very 
important for infants, and breast-fed infants have a gut microbiota that is dominated by bifidobacteria [8]. Breast milk is a nutritious food containing the appropriate nutrients for the growing infant, and it can also have a significant impact on the gut microbial composition by virtue of being a source of prebiotics, which beneficially effect the infant by selectively stimulating the growth of one or a limited number of bacteria in the gut [9]. The prevalence of bifidobacteria in the gastrointestinal (GI) tract of breast-fed infants has been associated with reduced infection rates [10].

Human breast milk is the optimal nutrition during infancy, but the rates of breastfeeding from one country to another have dropped sharply for practical or medical reasons [11], so the study of infant formulas has been into people's horizons. The infant formula composition has been improved during the last decades to tend to resemble human milk. Cow's milk protein is one of the major sources of nutrition in formulas but due to difference in the ratio of protein and carbohydrate, the amount of protein per energy content has generally been higher in formula than in human milk to meet the protein and amino acid requirements of infants [12,13]. Numerous babies have been fed high-protein formula for years during the last decades; this infant formula was especially encouraged in at risk populations such as low birth weight babies who had suffered intra-uterine growth restriction to ensure a rapid post-natal catch up growth $[14,15]$, but the current tendency is to reduce protein level in formula for full term healthy babies [16]. A randomized double-blind controlled trial study to evaluate the bifidogenic effect of formula low in protein, allowing a composition closer to that of human milk [17], but the role of low levels of protein as modulators of intestinal microbiota, especially in combination with high levels of carbohydrates, has been poorly investigated.

Understanding the low levels of protein that influence the composition of the microbial community is crucial in regulating the microbiota, which will be need for further research. In this study, we performed multiplex pyrosequencing of the V1-V3 hypervariable regions of $16 \mathrm{~S}$ rRNA gene with Miseq Sequencing. The aim of this study was to compare the similarity of the gut microbiota of SD rats from three different feeding patterns: breast-fed; lowprotein, high-carbohydrate infant formula-fed; human breast milk-fed, and to ascertain how the infant formula low in protein influences early microbial colonisation in the neonatal SD rats' model.

\section{Results}

A total of 612547 reads and 2998 OTUs were obtained from the 18 samples through pyrosequencing analysis. Each library contains 22473 to 44525 reads, with different phylogenetic OTUs ranging from 93 to 245 (Table 1). We then compared the microbial richness, estimated by the
Chao1 and ACE index, and the biodiversity, assessed by a nonparametric Shannon index for the three groups. In our calculations, we took into account the OTU distance unit cutoff of 0.03 (Table 1). We found a high microbial diversity in the infant feces and detected 245 species at most, but the diversity of the infant intestinal microbiota with different feeding patterns was different; the diveristy of fecal microbiota from A group was higher than B and C groups. Using the parametric test for comparisons, we could find significant differences $(p<0.001)$ in richness and biodiversity between the $\mathrm{A}, \mathrm{B}$ and $\mathrm{C}$ samples at the OTU cutoff of 0.03 .

The rarefaction curves tend to approach the saturation plateau (Figure 1). The Good's coverage index reveals that $92 \%$ to $96 \%$ of the species were obtained in eighteen samples. The samples from A group (e.g., the samples of A1, A2, A3, A4 and A5 except A6) were plotted in the upper part .This rarefaction curve indicated a large variation in the total number of OTUs in different samples, but the sequence coverage was still sufficient to capture the diversity of the bacterial communities, whereas the OTUs density was larger in the upper layer than the lower parts. The samples from B and C groups were plotted in the lower parts. The same tendency was found in species accumulation curves and Shannon-Wiener curves, it tends to approach the saturation plateau, which meant that the database of $16 \mathrm{~S}$ rRNA gene sequences was very abundant, that reflected the vast major of microbial information (see Additional file 1 and Additional file 2).

\section{Taxonomic composition}

The eighteen samples comprised of different numbers of OTUs and OTU abundances. All sequences were classified from phylum to genus according to the program Mothur using the default setting. Sequences that could not be classified into any known group are assigned as no rank. These bacterial OTUs can be assigned into 11 different phyla, 44 families or 78 genera (Figure 2).

The representative sequences at phylum level were listed in Figure 3. Bacteroidetes, Firmicutes, Proteobacteria were common to the whole 18 libraries, which comprised $94.52 \%, 97.11 \%, 97.53 \%$ of the total reads in the libraries of A, B and C groups, respectively. Bacteroidetes was the most abundant division, comprising approximately from $18.79 \%$ to $66.75 \%$ reads across all samples, their mean OTUs abundance in A, B and C groups was $51.07 \%, 49.35 \%, 55.97 \%$ respectively. Firmicutes was the secondary bacterial phylum in A group (41.01\%), but its abundance in B and C groups was $18.11 \%$ and $15.77 \%$. The secondary bacterial phylum in B and $\mathrm{C}$ groups was Proteobacteria, its abundance was $29.40 \%$ and $25.67 \%$ respectively. Statistical analysis indicated that the absolute quantity of Bacteroidetes, Firmicutes and Proteobacteria 
Table 1 Richness and diversity indexes relative to each fecal sample (OTU cutoff of 0.03 )

\begin{tabular}{|c|c|c|c|c|c|c|c|}
\hline \multirow[t]{2}{*}{ ID } & \multirow[t]{2}{*}{ Threshold } & \multirow{2}{*}{$\begin{array}{l}\text { Number } \\
\text { of reads }\end{array}$} & \multirow{2}{*}{$\begin{array}{l}\text { Number } \\
\text { of OTUs }\end{array}$} & \multicolumn{4}{|c|}{ Alpha diversity } \\
\hline & & & & ACE & Chao1 & Shannon & Simpson \\
\hline A1 & 0.03 & 22473 & 235 & 266 & 263 & 3.87 & 0.0514 \\
\hline A2 & 0.03 & 32037 & 221 & 253 & 263 & 3.68 & 0.0466 \\
\hline A3 & 0.03 & 33278 & 245 & 261 & 258 & 3.55 & 0.0804 \\
\hline A4 & 0.03 & 39229 & 245 & 308 & 286 & 3.9 & 0.0392 \\
\hline A5 & 0.03 & 26630 & 223 & 257 & 254 & 3.62 & 0.062 \\
\hline A6 & 0.03 & 31644 & 161 & 193 & 202 & 3.23 & 0.0742 \\
\hline B1 & 0.03 & 27296 & 178 & 215 & 233 & 2.67 & 0.1518 \\
\hline B2 & 0.03 & 39824 & 143 & 218 & 192 & 1.85 & 0.3823 \\
\hline B3 & 0.03 & 35116 & 138 & 156 & 155 & 2.97 & 0.0862 \\
\hline B4 & 0.03 & 29869 & 153 & 173 & 176 & 2.45 & 0.2063 \\
\hline B5 & 0.03 & 37604 & 136 & 158 & 161 & 1.95 & 0.2763 \\
\hline B6 & 0.03 & 34103 & 170 & 200 & 221 & 2.73 & 0.1307 \\
\hline $\mathrm{C} 1$ & 0.03 & 44525 & 135 & 166 & 176 & 2.69 & 0.1097 \\
\hline C2 & 0.03 & 31091 & 134 & 172 & 165 & 2.2 & 0.2155 \\
\hline C3 & 0.03 & 37837 & 139 & 185 & 195 & 1.86 & 0.2737 \\
\hline C4 & 0.03 & 25521 & 107 & 140 & 148 & 2.08 & 0.2094 \\
\hline C5 & 0.03 & 41564 & 142 & 169 & 169 & 2.1 & 0.2695 \\
\hline C6 & 0.03 & 42906 & 93 & 111 & 108 & 1.87 & 0.291 \\
\hline$P$ value & & 0.227 & 0.0000127 & 0.00018 & 0.000219 & $3.58 \mathrm{E}-06$ & 0.002472 \\
\hline
\end{tabular}

( $p<0.05$ indicate significant differences).

$(\mathrm{p}<0.001)$ significantly differentiated A from $B$ group, and they also differentiated A from $C$ group $(p<0.001)$. The average reads of No_rank group in A, B and C groups was 64, 57 and 105 reads.

At family level, there were 6 shared families (abundance > $1 \%$ ) among the total 44 families exist in all samples (Figure 4), namely, Acidaminococcaceae, Bacteroidaceae, Enterobacteriaceae, Erysipelotrichaceae, Lachnospiraceae, and Porphyromonadaceae. The top 4 families in group A, by descending read abundance, were Lachnospiraceae (27.29\%), Bacteroidaceae (14.91\%), Porphyromonadaceae (14.08\%) and Prevotellaceae (9.60\%) respectively. The top 4 families in $B$ and $C$ groups were same, which were Bacteroidaceae (35.94\% versus 43.24\%), Enterobacteriaceae $(28.46 \%$ versus $25.52 \%)$, Porphyromonadaceae (12.35\% versus12.53\%) and Lachnospiraceae (11.22\% versus $7.61 \%$ ), whereas the fifth family in B and C groups was Verrucomicrobiaceae (2.28\%) and Erysipelotrichaceae (3.80\%). From the Figure 4, it was obvious that the gut microbiota of $B$ between $C$ groups at the family level had high similarity.

Detected OTUs were distributed among 78 different bacterial genera. Bacteroides was the most abundant division (Figure 5), comprising approximately from 1909 to 22073 reads across all samples, their mean OTUs abundance in A, B and C groups was 14.91\%, 35.94\%, $43.24 \%$ respectively, and it was the most abundant genus in $\mathrm{B}$ and $\mathrm{C}$ groups, but unclassified genus was the most abundant species in A group, its mean abundance was $15.04 \%$. The secondary genus in B and $C$ groups was Escherichia-Shigella; its mean abundance was $27.06 \%$ and $25.06 \%$. The third genus in B and C groups was Parabacteroides, its mean abundance was $12.22 \%$ and $12.49 \%$, interestingly, this genus in A group was the same place. Lactobacillus was one of the most famous probiotics, its mean abundance was $2.82 \%$ in A group, but it was not easy to be find in $\mathrm{B}$ and $\mathrm{C}$ groups. The mean abundance of S24-7_norank genus in A group was 9.47\%, which was 10 fold in B group, and 90 fold in $C$ group.

\section{Bacterial community variation}

The hierarchical cluster analysis (Figure 6) using MVSP 3.1 software showed that the $\mathrm{B}$ and $\mathrm{C}$ communities grouped together, and then clustered with the A communities in order. The principal component analysis with the weighted UniFrac distance and heatmap analysis were determined using pyrosequencing data to corroborate further the findings from these DNA fingerprinting methods. The principal component analysis (PCA) score plot revealed that the A communities harbored characteristic bacterial communities, and the entire A samples grouped to the left of the graph along $\mathrm{PC} 1$, which accounted for $54.8 \%$ of the total variations. The B and $\mathrm{C}$ samples were closely related, whereas the B2 sample was separate from 


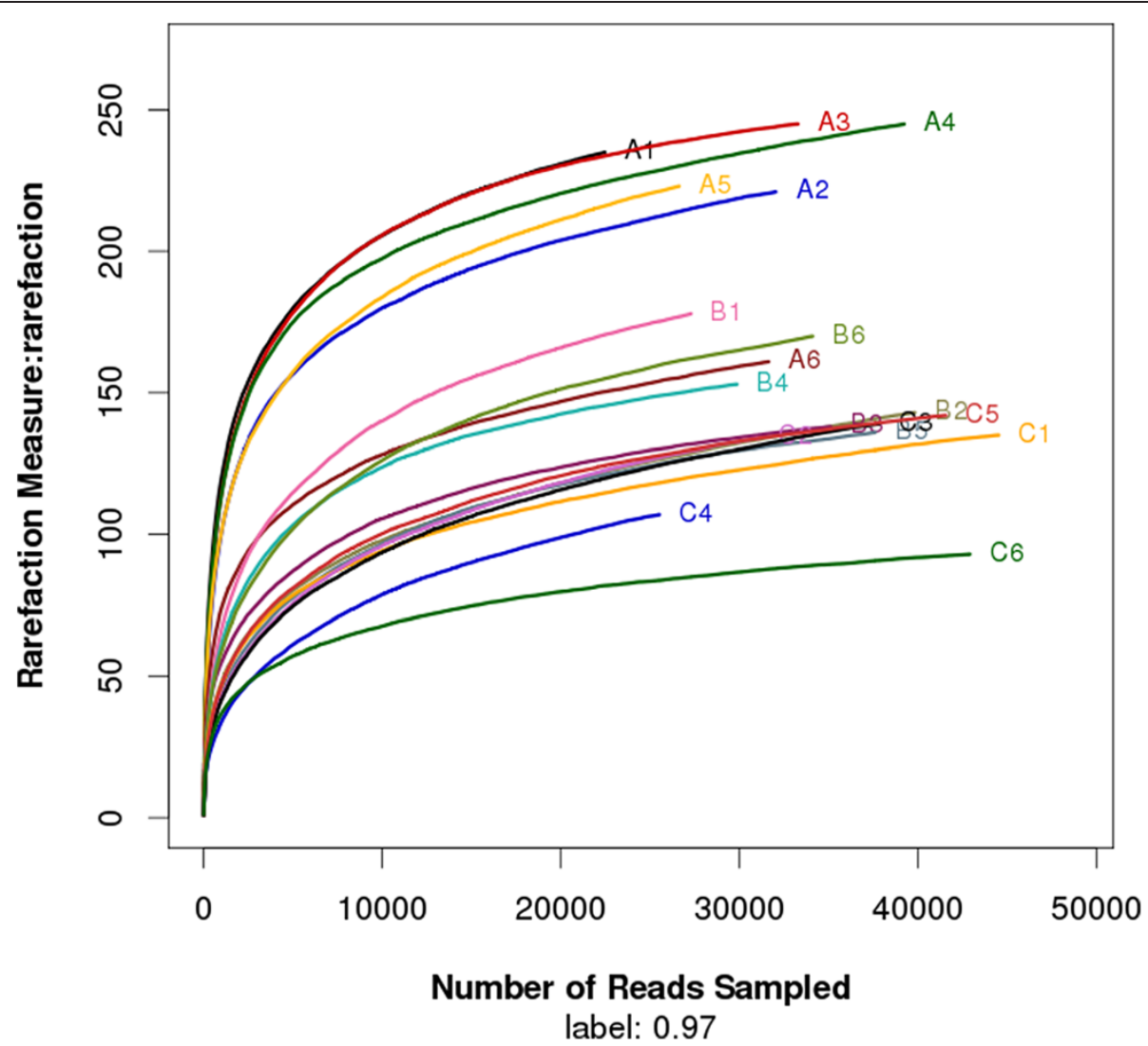

Figure 1 Rarefaction analysis of the different samples. Rarefaction curves of OTUs clustered at 97\% phylotype similarity level.

the other samples along PC2, which represented 27.88\% of the total variations (Figure 7). Overall, the two PCA axes explained $82.68 \%$ of the variation between the different communities. The NMDS analysis based on the BrayCurtis distance, also confirmed bacterial communities in A group were more similar than the $\mathrm{B}$ and $\mathrm{C}$ groups (Figure 7). The direction and position of the environmental factors, calculated with the envfit function in the $R$ vegan package [18], suggested the bacterial community in the SD rats' gut micro biota was somewhat related to the feeding mode. However, the correlation did not reach statistical significance. Species rank abundance distribution curves (see Additional file 3) revealed that the OTUs present in five libraries (A1-A5) contained the most abundant OTUs in any library, whereas the OTUs observed in other libraries seemed to be relatively low in diversity. The hierarchical heatmap was based on abundant bacterial community at genus level, which generally indicates three groups (Figure 8). One was mainly composed of A4, A6, B3, C1, $\mathrm{A} 1, \mathrm{~A} 2$ and $\mathrm{A} 5$ samples; the other group was chiefly clustered by other samples (B2, C2, B5, C3, B6, C4, A3, B1, C6, $\mathrm{B} 4$ and $\mathrm{C} 5$ ). According to the heat map, high similarity of the communities could be found in the samples from A group, and relatively high similarity was also found in B and $\mathrm{C}$ groups. The species shared among these communities were determined via a Venn diagram to compare the relationships among these communities in detail. The result showed that the number of species shared in A (A1-A4), B (B1-B4) and C (C1-C4) communities was 155, 83 and 62 respectively, which showed A group had higher number of shared species (Figure 9).

\section{Discussion}

Infant complex intestinal microbial communities are believed to provide some benefits to their host [5]. The course of microbial colonization of the newborn gut is determined by a complex interaction of factors, in addition to genetics, dietary habits, and sedentary life styles, altered nutritional experiences in early life via malprogramming effects in target organs, and also contribute to the ecology of the gut microbiota. In several of feeding patterns, the breast-fed is the best feeding mode. The ability of breast milk to modulate the composition of the infant gut microbiota contributes to its beneficial health effects. Among the properties of breast milk affecting the development of the infant gut microbiota are the type and quantity of protein and carbohydrate [19]. The rate of breast fed has been declining; many types of infant formulas have now received increasing attention. Diets that are high in protein but reduced in carbohydrate contents provide a 


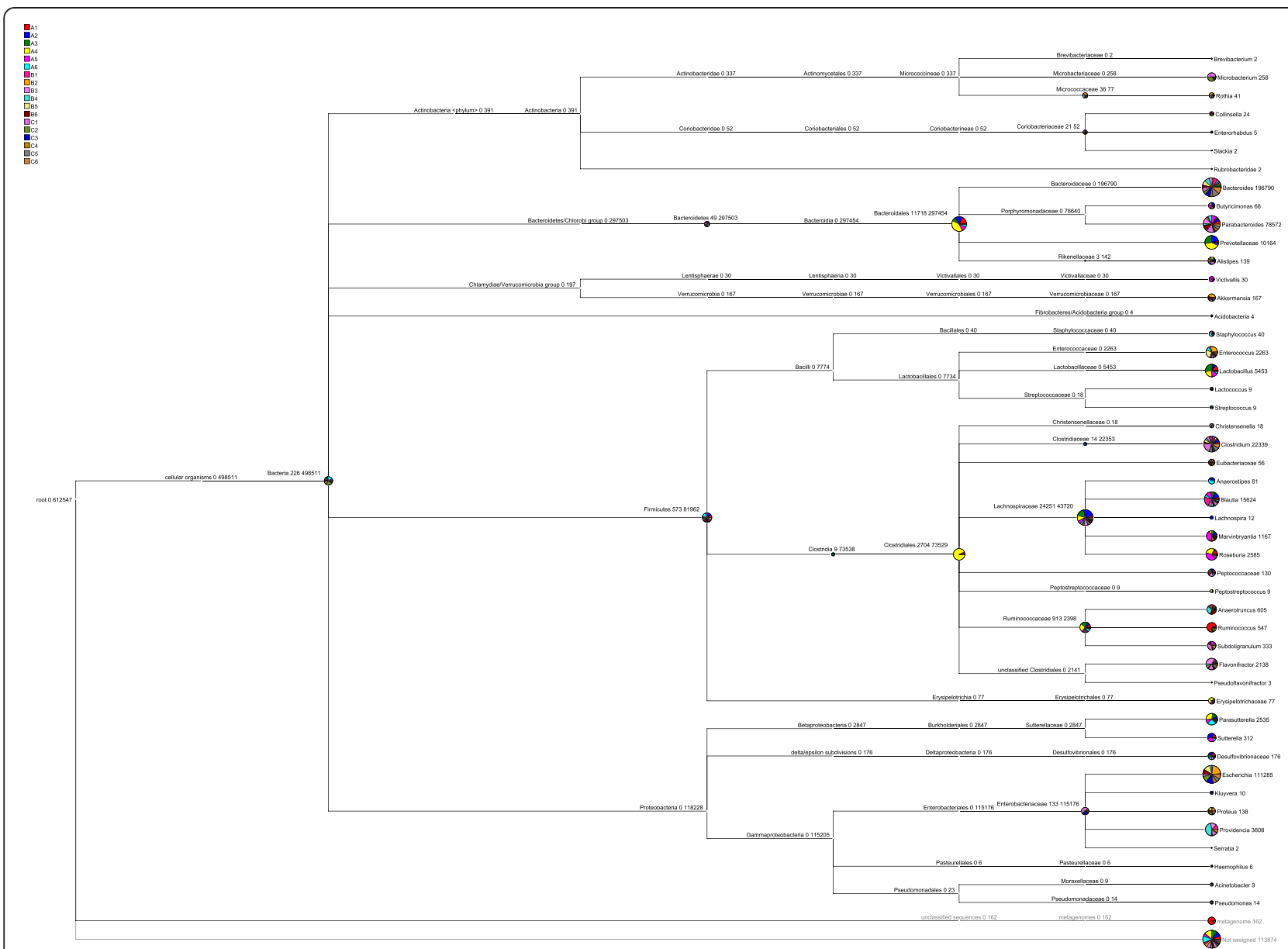

Figure 2 Representative bacterial community composition in large intestine of different vegetation classes. Shown are the percentages of the classified sequences. Representative pyrosequencing reads were selected from each group of the OTUs clustered within the $3 \%$ genetic distance by the MOTHUR program.

common approach for achieving weight loss, but longterm adherence to such diets may increase risk of colonic disease [20]. HP diet consumption should be considered with some caution because of its ability to modify the composition of the luminal content and the morphology and metabolic oxidative capacity of colonic epithelial cells in rats [21]. In the studies of weaned piglets, fermentation of high protein often coincided with the growth of potential pathogens, thereby increasing the risk for infectious diseases. In the meantime, fermentation of dietary protein could produce detrimental substances, including ammonia, amines and phenols, these substances have been associated
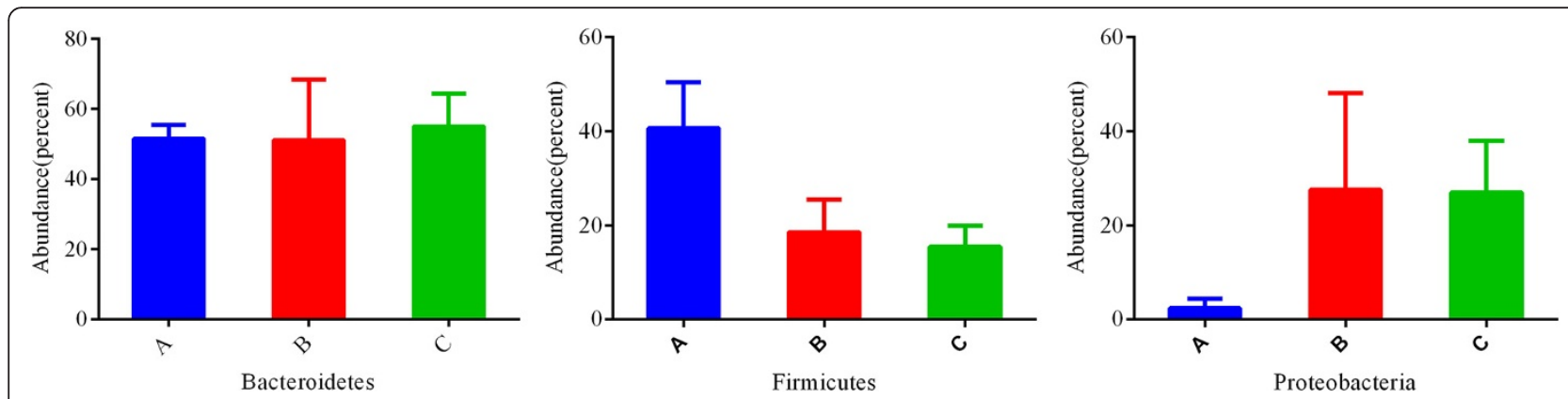

Figure 3 Relative abundance of the intestinal flora at the phylum level in infants (percent). The mean abundance of the intestinal flora at the phylum level in breastfed pups (A). The mean abundance of the intestinal flora at the phylum level in weaned pups fed on formula (B). The mean abundance of the intestinal flora at the phylum level in weaned pups fed on human breast milk (C). 


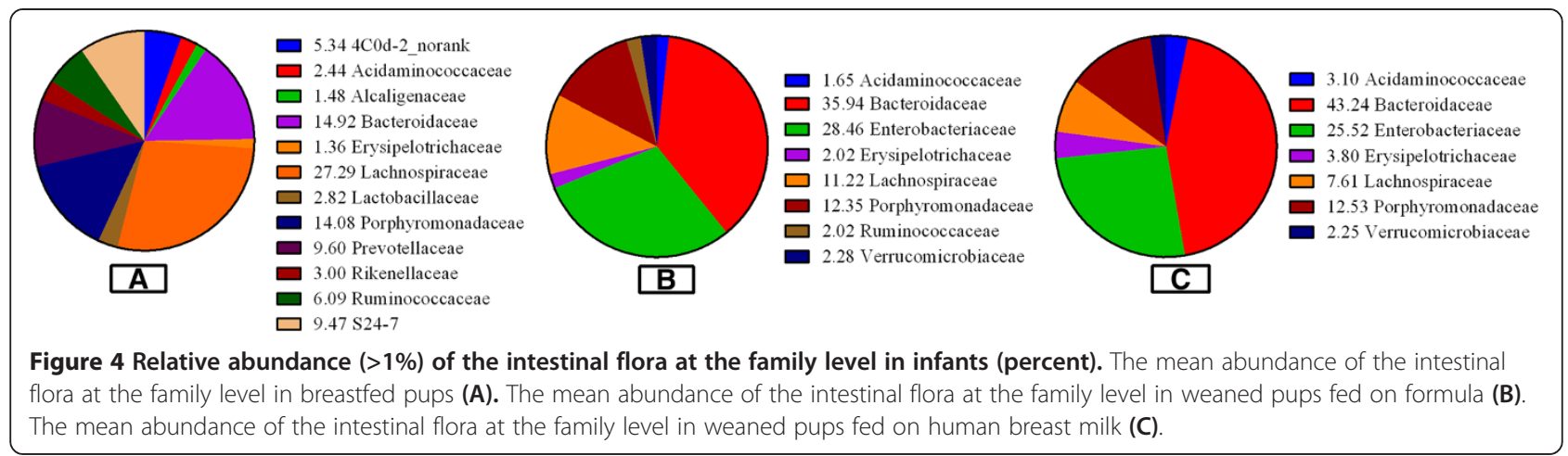

with various detrimental effects for the host animal [22]. Reducing dietary crude protein (CP) level, as a strategy to solve the problems, has been found to limit the frequency and the severity of digestive problems in piglets [23]. At the same time, reducing the amount of dietary protein has also been proved as an alternative option to avoid excessive protein fermentation [24], and this approach potentially contributed to improvements in health conditions and growth performance [25]. Another study has been shown that reducing dietary intake of protein could improve gut function after weaning [26]. Low protein formulas have begun to be used in neonates, its effect allowing a composition closer to that of human milk [17]. Apart from the low protein, the high carbohydrate diet have received more and more attention, one study have been investigating the long-term consequences of altered postnatal nutrition independent of fetal effects by artificially rearing neonatal rat pups on a high-carbohydrate (HC) milk formula during the suckling period, they found high-carbohydrate pups correlates with several adaptations in pancreatic $\beta$ cells including the autonomic regulation of insulin secretion, and the source of calories varied (from fat-rich in rat milk or the high-fat $(\mathrm{HF})$ milk formula to high carbohydrate in the $\mathrm{HC}$ milk formula) within the context of an isocaloric and isonitrogenous milk formula [27,28]. In the context, the effect of high protein infant formula did not allow a composition closer to the human milk and may lead to some risk, we did not design a group of rats fed with high protein infant formula. In the study, we performed multiplex pyrosequencing of the V1-V3 hypervariable regions of $16 \mathrm{~S}$ rRNA gene of the SD rats' gut microbiota with Miseq Sequencing, the SD rats from three different feeding patterns: breast-fed; low-protein, high-carbohydrate infant formula-fed; human breast milk-fed, and to compare the similarity of the gut microbiota of the SD rats from different feeding patterns, and our results could

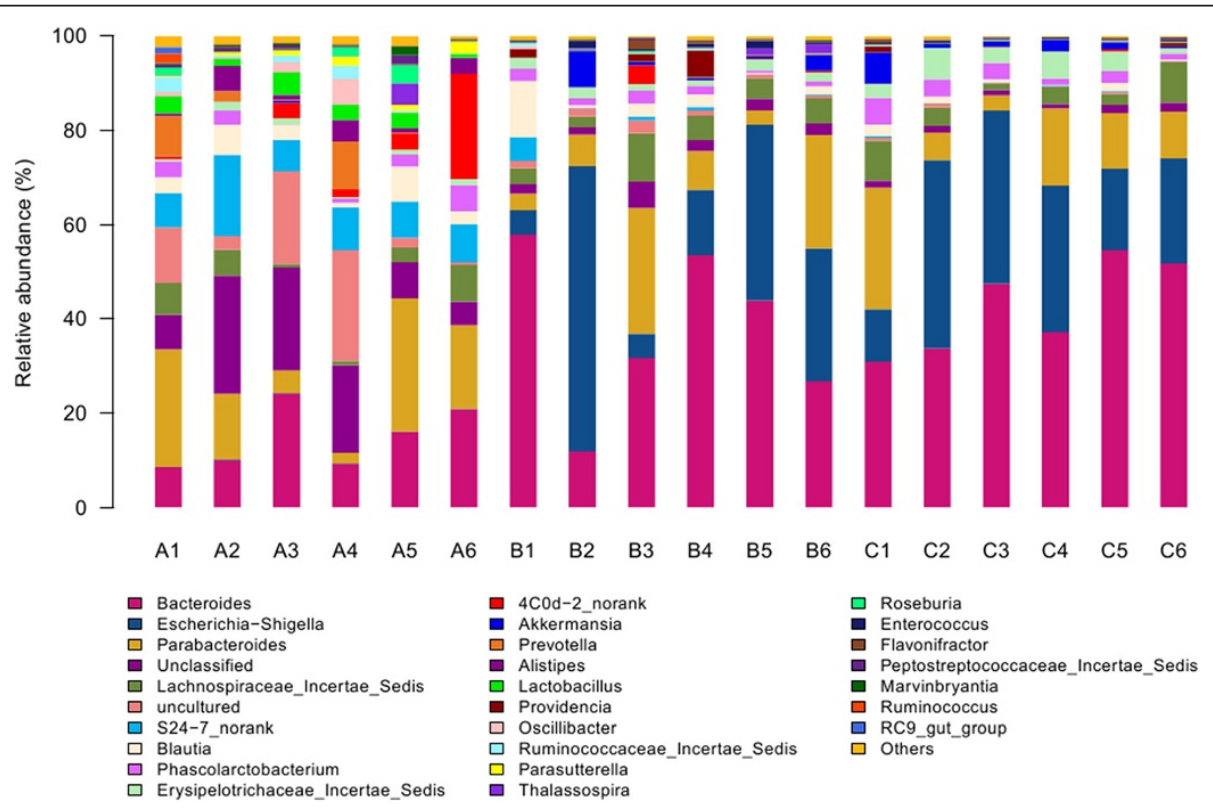

Figure 5 Bacterial composition of the different communities at the genus level. Relative read abundance of different bacterial genus within the different communities. Sequences that could not be classified into any known group were assigned as No_Rank. 


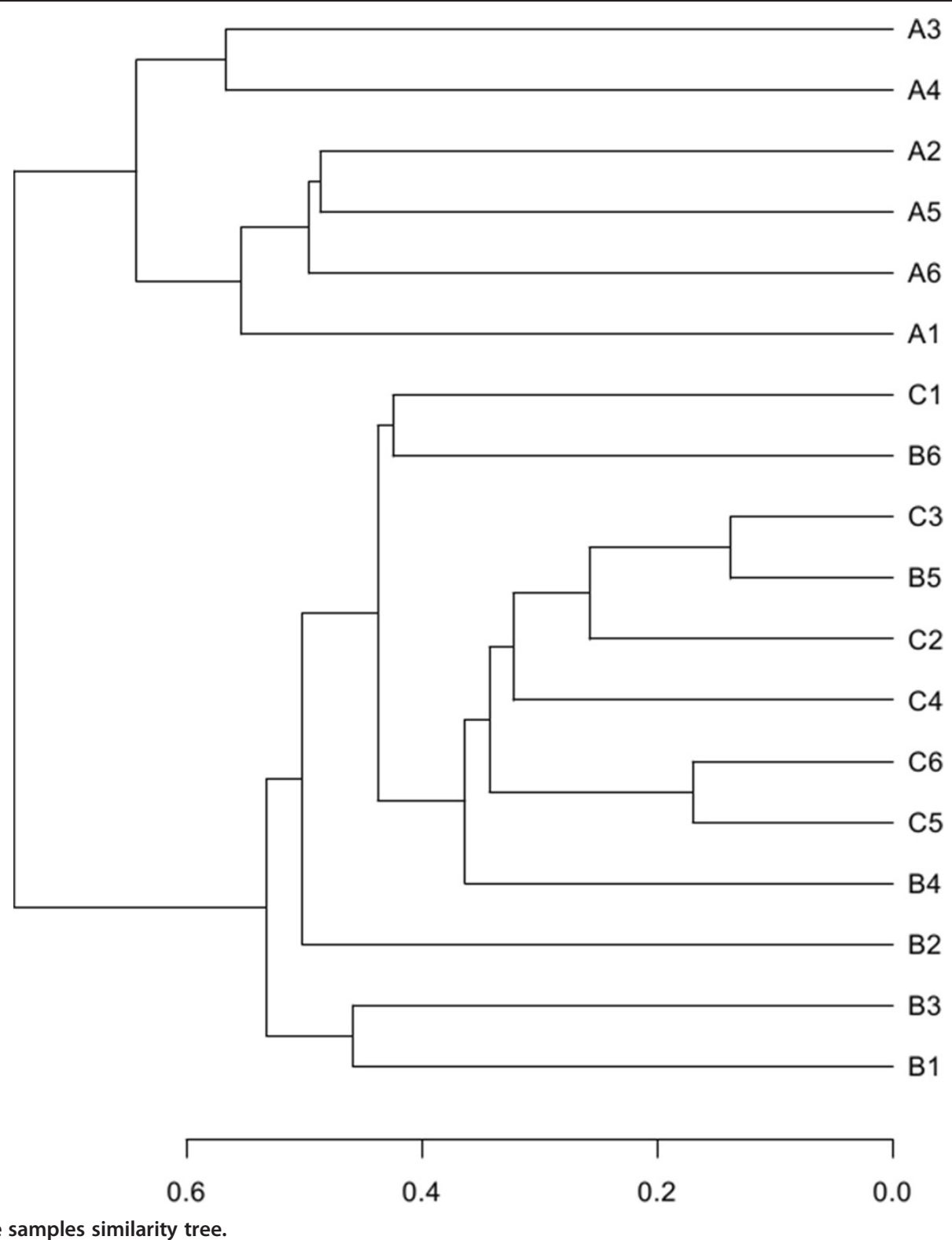

provided a theoretical and technical support for future studies of the infant formulas.

The major finding of our study was that feeding rat neonates a low protein with high carbohydrate formula induced dramatic changes in the developmental profile of SD rats' intestinal microbiota. Indeed feeding neonate rats LP (low-protein) formula and human breast milk both decreased bacterial abundance and diversity in the large intestine, while the bacterial abundance and diversity in the large intestine of low- protein with high-carbohydrate infant formula-fed rats between human breast milk-fed rats was similar. Bacteroidetes, Firmicutes, Proteobacteria occupied $94.52 \%, 97.11 \%, 97.53 \%$ of the total reads in the libraries of $\mathrm{A}, \mathrm{B}$ and $\mathrm{C}$ groups, respectively, which were the dominating gut microbiota, in agreement with the previous study describing such phyla as those contributing to the majority of infant gut microbiota [29], but the absolute quantity of Bacteroidetes, Firmicutes and Proteobacteria ( $\mathrm{p}<0.001$ ) significantly differentiated A from B and C groups. The abundance of Bacteroidetes was the highest in three groups, Proteobacteria was the most secondary abundant, followed by Firmicutes in B and C groups, which was inconsistent with the previous study [30], the incongruence may probably be due to the differences in host and the host living conditions. Surprisingly, the phylum generally made up a very small proportion of bacterial sequences retrieved from rats' intestine, which was agree with the Claesson's study [31]. There were 6 


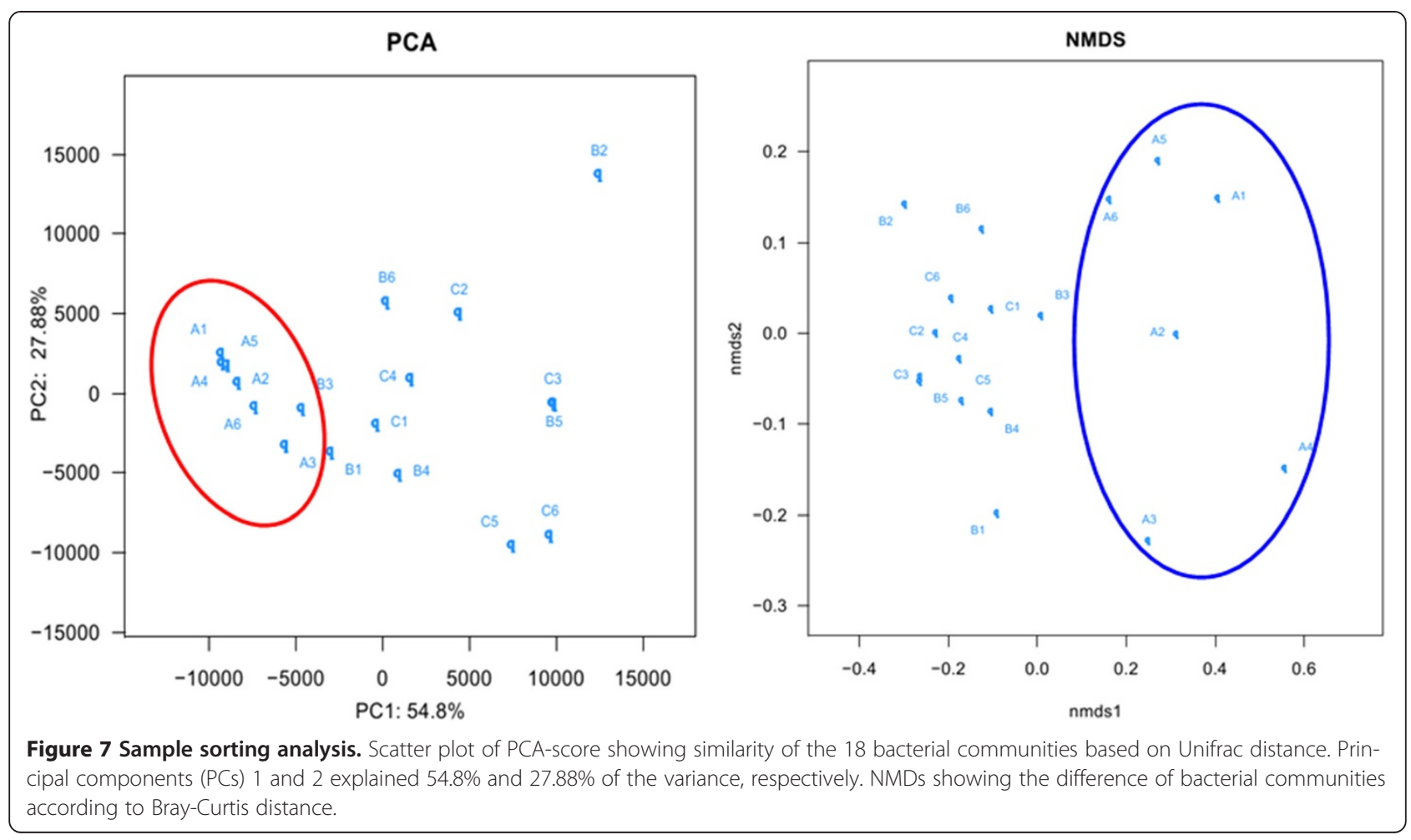

shared families (abundance $>1 \%$ ) among the total 44 families exist in all samples at family level. The most abundant microbiota at the family level was the Lachnospiraceae in A group, but the most abundant microbiota at the family level was the Bacteroidaceae $\mathrm{B}$ and $\mathrm{C}$ groups. Interestingly, the abundance, diversity and species (abundance > $1 \%$ ) of $B$ and $C$ group almost the same from Figure 4. At the genus level, Bacteroides was the most abundant division in three groups. Probiotics have been widely used; they may prevent pathogens from proliferating in the intestinal tract, and in the culture environment and may improve condition by securing optimal use of the feed, or stimulating the immune system of the host [32]. As one of the most famous probiotics, the mean abundance of Lactobacillus was 2.82\% in A group, but it was not easy to be found in B group. The reason may be the breast milk have a strong prebiotic effect for the neonate's developing microbiota [33], and it may supply directly this microbiota [34]. Surprisingly, Lactobacillus was not also found in the human breast milk-fed group, which may probably be due to the different physiological structure and function between rats and human, and the host living conditions. Actinobacteria were prevalent members of the intestinal bacterial communities and they were more abundant in the study, which are widely distributed in both terrestrial ecosystems, and they played a crucial role in the recycling of refractory biomaterials through decomposition and humus formation, the production of their secondary metabolites were potent antibiotics [35], but in the study, there was a strong DNA extraction bias which was evident by absence of Actinobacteria (including Bifidobacterium spp.) in the analysed samples, differ considerably from many previous studies, they have reported that the microbiota of breast-fed infants was dominated by Bifidobacteria [36,37], but it was consistent with the previous study [38], it showed that Bifidobacteria were not appear at a specific period after birth, and thereafter persisted as a minority population, and they also pointed out Bifidobacteria in studies of the infant GI microbiota may be excessive emphasis on its role to health. Although such technical error caused some shift in the detected microbial community, we thought the results presented here suggest numerous future avenues of research.

Intestinal microbiota has been widely recognized in the context of mammalian hosts [39]. In the present study, PCA and heatmap plots of the bacterial communities derived from SD neonate rats, and the 16S rRNA gene fingerprinting based analyses, suggested that the rats harbored different intestinal microbiota from A group from $\mathrm{B}$ and $\mathrm{C}$ groups, and showed that the gut bacterial communities were more similar to the B and $\mathrm{C}$ groups than the A group. Species rank abundance distribution curves indicated that A group also contained the most abundant OTUs in any library, whereas the OTUs observed in other libraries tended to be relatively low in abundance. In addition, the Venn diagram indicated that A group shared more species than the B and C libraries, 


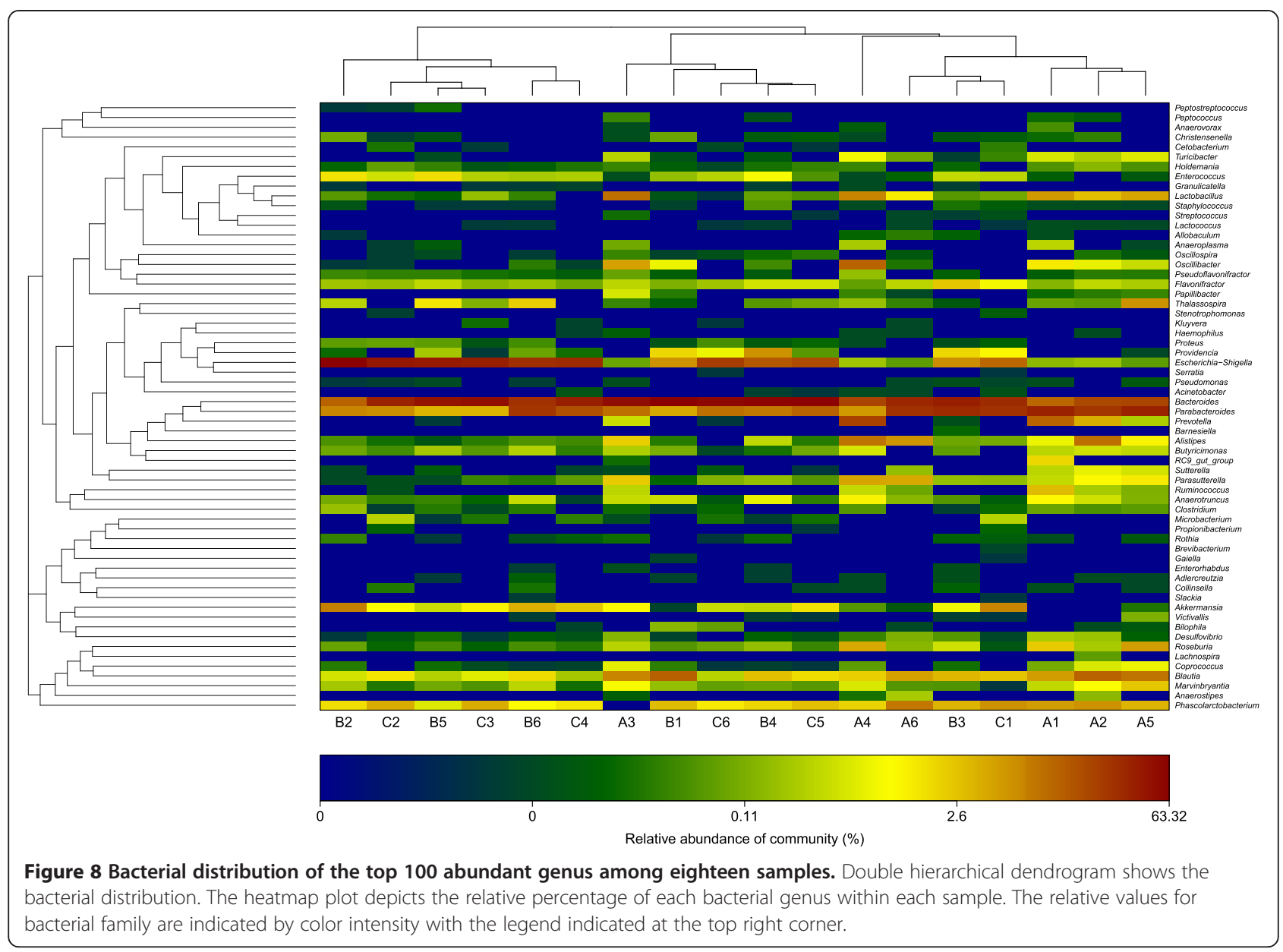

each group had core intestinal microbiota. These results indicated that feed might significantly influence the composition of the gut microbiota.

\section{Conclusion}

Although it is now apparent that the feeding pattern is not the sole determinant of the levels of bacteria in the infant gut, it is clear that feeding does have a crucial impact. Rats from formula and human milk group suffered substantial stress, were forced fed, had no contact with adult rats, and were maintained in the same living circumstance, and the level of protein with high carbohydrate in formulas did have immediate consequences on gut ecology, we concluded the composition of the formula may be the factor causing similar microbiota profiles. The study provided a more comprehensive understanding of the structure and diversity of the intestinal microbiota diversity in three different feeding modes. Furthermore, such low protein formula-fed also had high similar bacterial abundance and diversity with human breast milk fed rats, it could provide us a new idea for future studies of the infant formulas.

\section{Methods}

Animals

A total of 36 pups, derived from a breeding colony of SD rats supplied by Vital River Laboratory Animal Technology Co. Ltd., were used in this study. The progenitor mice were 8 weeks of age and were acclimatized for 30 days prior to breeding. All the rats were determined to be healthy on the basis of individual physical examinations and pathogen free based on results of the routine microbiological screening performed in the colony. All the rats were maintained in stainless steel Eurostandard Type II cages $(36.5 \times 20.7 \times$ $14.0 \mathrm{~cm}$ ) protected with filter tops. The cages had solid bottoms, were covered with Aspen chip bedding and were provided with some nesting material. The environment in the room consisted of a temperature range of $23^{\circ} \mathrm{C}\left( \pm 3^{\circ} \mathrm{C}\right)$, a relative humidity of $55 \pm 15 \%$ and an artificial illumination of a 12-h light/dark cycle. They were maintained on a standard laboratory diet and were allowed free access to water.

Day of birth was referred to as Day 0 of neonatal life. At the commencement of the study, all the pups were 14 days of age, and their mean body weight was $33.27 \pm 1.01 \mathrm{~g}$. Throughout the study period, all the pups in the breastfed group (A group) had free access to the dam's nipples, the 


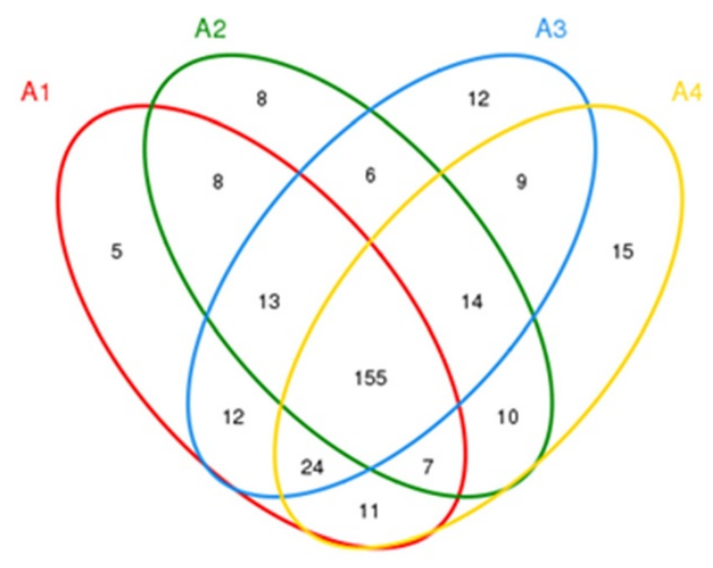

Unique objects: $\mathrm{All}=309 ; \mathrm{S} 1=235 ; \mathrm{S} 2=221 ; \mathrm{S} 3=245 ; \mathrm{S} 4=245$

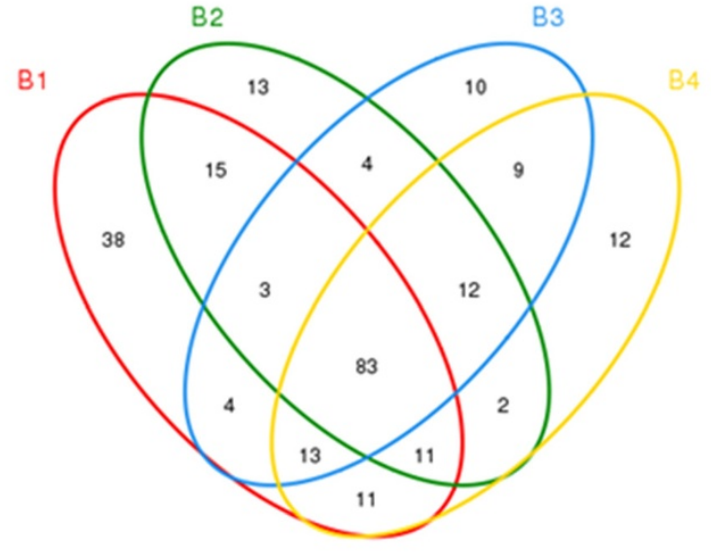

Unique objects: $A$ II $=240 ; S 1=178 ; S 2=143 ; S 3=138 ; S 4=153$

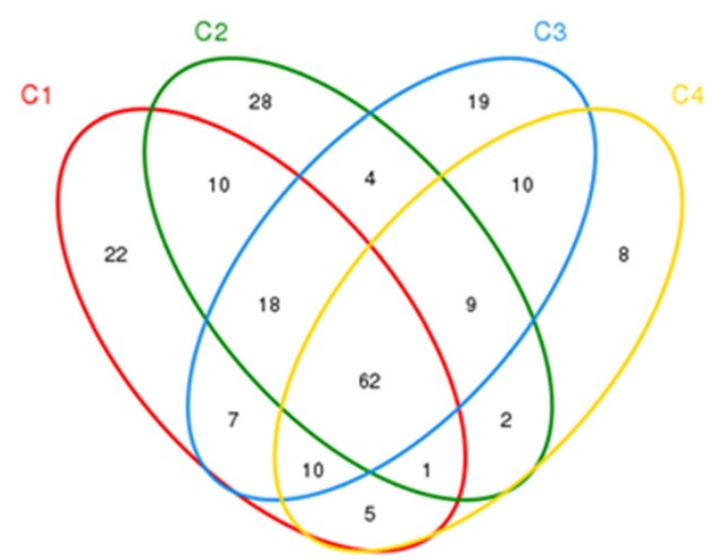

Unique objects: $\mathrm{All}=215 ; \mathrm{S} 1=135 ; \mathrm{S} 2=134 ; \mathrm{S} 3=139 ; \mathrm{S} 4=107$

Figure 9 Venn diagram showing the unique and shared OTUs (3\% distance level).

pups in formula-fed group (B group) had free access to a standard moist diet (Table 2) consisting of a porridge made by adding warm water to an infant formula at a final proportion of $65 \mathrm{~g}$ of infant formula/15 $\mathrm{mL}$ of water, the pups in $\mathrm{C}$ group had free access to human breast milk, which was bought in Harbin city maternal and child health care center, Heilongiiang province. The $\mathrm{B}$ and $\mathrm{C}$ groups were administered with $1.0-\mathrm{mL}$ diet every $4 \mathrm{~h}$, including nighttime, using sterile $1.5-\mathrm{mL}$ syringes attached to specialized feeding needles before killing. Each group had a separate feeding needle. After each feeding, the needles were washed, resterilized, and stored in labeled, sealed, sterile conical tubes until the next feeding time. The 1.5-mLsyringes were discarded after each feeding. The pups were weighed and measured daily for weight loss or gain. All the adult rats were fed a standard mouse chow adlibitum. Tap water was provided without restrictions to adult and infant mice in polycarbonate bottles. The animals were weighed daily during the intervention study and handling was done in the same time range to avoid the influence of biological rhythms.
This study was performed at the Northeast Agricultural University. Pilot experiments were performed to optimize all the experimental procedures including handling and treatments. The experimental protocol was approved by the Institutional Animal Care and Use Committee of Northeast Agricultural University under the approved protocol number SRM-06.

\section{Study design}

The animals were randomly assigned to dietary intervention groups and treated as described in Figure 10. Intervention was given for 7 days. The study groups were breastfed (unweaned) pups (A group, $\mathrm{n}=12$ ); weaned pups fed on formula ( $B$ group, $n=12$ ); and weaned pups fed on human breast milk ( $C$ group, $n=12)$. After 7 days, we selected 6 rats at random from each group to study.

\section{Fecal sample collection and DNA extraction}

After the 7-day diet intervention, the animals were anesthetized with isoflurane and samples were collected. Immediately after euthanasia by cervical dislocation, the entire 
Table 2 Nutrient content of the formula

\begin{tabular}{|c|c|c|c|}
\hline Nutrient & Standard & Nutrient & Standard \\
\hline Energy (kcal) & 100 & Iron (mg) & 1.15 \\
\hline Protein (g) & 1.8 & Zinc (mg) & 1.2 \\
\hline a-lactoalbumin (g) & 1.08 & Copper $(\mu \mathrm{g})$ & 38 \\
\hline L-carnitine(mg) & 14 & lodine $(\mu \mathrm{g})$ & 16 \\
\hline Arachidonate $(\mu g)$ & 20 & Selenium ( $\mu g$ ) & 6 \\
\hline $\begin{array}{l}\text { Aocosahexaenoic } \\
\text { acid }(\mu \mathrm{g})\end{array}$ & 1 & Vitamin A $(\mu \mathrm{g})$ & 116 \\
\hline Linoleic acid (mg) & 900 & Vitamin D $(\mu g)$ & 1.7 \\
\hline a-linoleic acid (mg) & 90 & Vitamin E (IU) & 2.6 \\
\hline Carbohydrate (g) & 10.2 & Vitamin K ( $\mu \mathrm{g})$ & 15 \\
\hline $\begin{array}{l}\text { Galactooligosaccharide } \\
\text { (g) }\end{array}$ & 0.14 & Thiamine ( $\mu g$ ) & 174 \\
\hline $\begin{array}{l}\text { Fructo-oligosaccharide } \\
\text { (g) }\end{array}$ & 0.05 & Riboflavin $(\mu \mathrm{g})$ & 280 \\
\hline Fat (g) & 5.37 & Niacin $(\mu g)$ & 870 \\
\hline Calcium (mg) & 117 & Pantothenic acid $(\mu \mathrm{g})$ & 1062 \\
\hline Phosphorus (mg) & 75 & $\begin{array}{l}\text { Pyridoxin, vitamin B-6 } \\
(\mu \mathrm{g})\end{array}$ & 108 \\
\hline Sodium (mg) & 49.5 & $\begin{array}{l}\text { Cobalamin, vitamin B- } \\
12(\mu \mathrm{g})\end{array}$ & 0.38 \\
\hline Potassium (mg) & 105 & Folic acid $(\mu g)$ & 29 \\
\hline Chloride (mg) & 145 & Vitamin C (mg) & 19.7 \\
\hline Magnesium (mg) & 6.25 & Choline (mg) & 21.2 \\
\hline Taurine (mg) & 1.38 & Biotin(mg) & 3.3 \\
\hline Myo-inositol (mg) & 20 & & \\
\hline
\end{tabular}

Note: All nutrients are expressed per $100 \mathrm{kcal}$ except Energy.

intestinal tract was removed from the pups on Day 21. The full contents of the large intestines were emptied, and were placed into sterile polypropylene centrifuge tubes and stored provisionally in a portable refrigerator at $-20^{\circ} \mathrm{C}$, and transferred to laboratory within 24 hours and kept frozen at $-80^{\circ} \mathrm{C}$ until DNA extraction. DNA was extracted according to the protocol described by the E.Z.N.A Soil DNA Kit (OMEGA).

\section{PCR amplification and pyrosequencing}

A region, $506 \mathrm{bp}$ in the $16 \mathrm{~S}$ rRNA gene, covering the V1-V3 region was selected to construct community library through tag pyrosequencing. The bar-coded broadly conserved primers $27 \mathrm{~F}$ and 533R containing the A and B sequencing adaptors were used to amplify this region. Universal bacterial primer set 27 (5'-3' AGAGTTT GATCCTGGCTCAG) and 533R (5'-3' TTACCGCGGCT GCTGGCAC) covering V1-V3 regions of SSU were synthesized by Shanghai Majorbio Bio-pharm Technology Co., Ltd. (Majorbio as below). Different barcode sequences were added at the 5 ' end of the forward primer for multiplexed pyrosequencing. PCR were carried out in a $20 \mu \mathrm{L}$ reaction volumes containing 10 ng DNA template, $2 \mu \mathrm{L}$ dNTPs $(2.5 \mathrm{mM}), 0.4 \mu \mathrm{L}$ of each primer $(5 \mu \mathrm{M})$ and 0.4 U $\mu \mathrm{L}$ FastPfu Polymerase (Applied Biosystems) in the appropriate 56 FastPfu Buffer $(4 \mu \mathrm{L})$ and de-ionized ultrapure water (to $20 \mu \mathrm{L}$ ). The protocol was optimized with low cycles for better accuracy and reliability of the subsequent data analysis. The PCR condition were initial denaturation at $95^{\circ} \mathrm{C}$ for $2 \mathrm{~min}$, followed by 25 cycles of denaturation at $95^{\circ} \mathrm{C}$ for $30 \mathrm{~s}$, annealing at $55^{\circ} \mathrm{C}$ for $30 \mathrm{~s}$ and extension at $72^{\circ} \mathrm{C}$ for $45 \mathrm{~s}$, with a final extension phase at $72^{\circ} \mathrm{C}$ for $10 \mathrm{~min}$. PCR products $(3 \mu \mathrm{L})$ were checked on a $2 \%$ agarose gel. PCR products were purified using MiniElute PCR purification kit (AXYGEN) and quantified using the ABI GeneAmp 9700 system. Samples were then pooled at equal concentrations. Parallel tagged sequencing was performed using a Miseq Sequencing in Majorbio.

\section{Bioinformatic analysis}

Data preprocessing was performed mainly upon software of mothur [40]. These sequences were clustered to OTUs (operational taxonomic units) at 97\% sequence

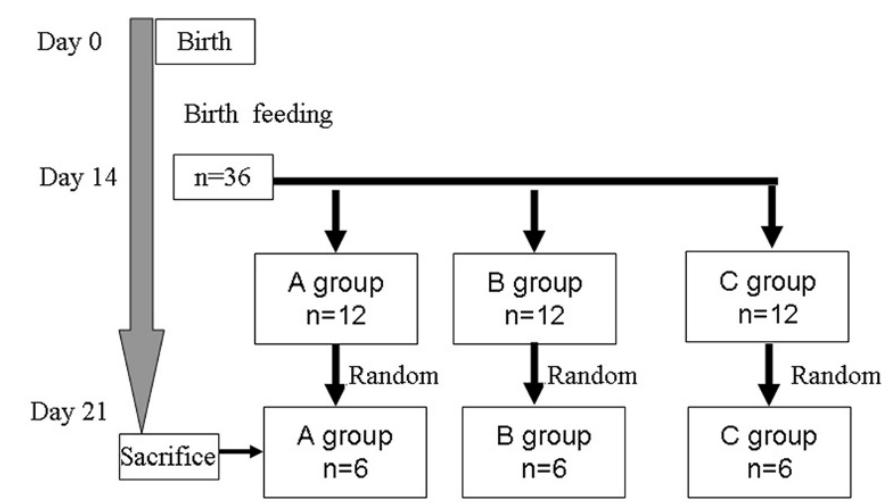

Note: A group (breast fed), B group (formula fed), C group (human milk breast fed)

Figure 10 Experimental study design. 
identity by using mothur (furthest neighbor method) and chopseq (Majorbio). Rarefaction analysis was performed by mothur and plot-rarefaction (Majorbio). From these, the Shannon diversities and the Chaol richness estimations were calculated by mothur. The weighted UniFrac distance was used to quantify differences in community composition. Heatmap figure and Venn diagrams were implemented by $\mathrm{R}$ packages heatmap [41] and Venn diagram [42], respectively. In addition, wei ghted principal component analysis (PCA) and Nonmetric Multidimensional Scaling (NMDS) diagrams were generated by using $\mathrm{R}$ package vegan [18] to demonstrate the clustering of different samples.

\section{Statistical analyses}

Differences between populations had been analyzed using parametric (ANOVA) and nonparametric statistical methods. All results are presented as the mean value $( \pm \mathrm{SE})$. Differences between groups were declared significant at $\mathrm{p}<0.05$.

\section{Availability of supporting data}

$16 \mathrm{~S}$ rRNA gene sequences supporting the results of this article are available in the GenBank Database (https:// www.ncbi.nlm.nih.gov/genbank/) under the accession number SRP048909.

\section{Additional files}

Additional files 1: Figure S1. Shannon Wiener curves of samples.

Additional files 2: Figure S2. Species accumulation curves.

Additional files 3: Figure S3. OTU Rank-Abundance curves.

\section{Abbreviations}

ANOVA: Analysis of variance; DNA: Deoxyribonucleic acid; PCR: Polymerase chain reaction; SE: Standard error; PCA: Principal component analysis.

\section{Competing interests}

The authors declare that they have no competing interests.

\section{Authors' contributions}

WF was involved experimental design, recruited subjects, collected specimens, performed experiments including data analyses, and wrote the first draft of the manuscript. YT was provided in put into experimental design, data analyses and other important technical support associated with the experiments. YQ was involved in experimental process. FC was involved experimental design. GH was involved in experimental design, data analyses and interpretation, and edited drafts of the manuscript. All authors have read and approved the final manuscript.

\section{Acknowledgements}

This work was supported by the grants from the National High Technology Research and Development Program of China (863 Program)

(No. 2011AA100902 and 2012AA022108). The authors wish to thank the Synergetic Innovation Center of Food Safety and Nutrition for funding this study.

\section{Author details}

${ }^{1}$ Key Laboratory of Dairy Science, Ministry of Education, Northeast Agricultural University, Harbin 150030, China. ${ }^{2}$ Hei LongJiang Polytechnic, Harbin 150111, China.

Received: 8 April 2014 Accepted: 30 October 2014

Published online: 18 November 2014

\section{Reference}

1. Bjorksten B: The gut microbiota: a complex ecosystem. Clin Exp Allergy 2006, 36:1215-1217.

2. Ley RE, Lozupone CA, Hamady M, Knight R, Gordon Jl: Worlds within worlds: evolution of the vertebrate gut microbiota. Nat Rev Microbiol 2008, 6:776-788

3. Rawls JF, Samuel BS, Gordon J: Gnotobiotic zebrafish reveal evolutionarily conserved responses to the gut microbiota. Proc Natl Acad Sci U S A 2004, 101:4596-4601.

4. Young VB: The intestinal microbiota in health and disease. Curr Opin Gastroenterol 2012, 28:63-69.

5. Flint HJ, Bayer EA, Rincon MT, Lamed R, White BA: Polysaccharide utilization by gut bacteria: potential for new insights from genomic analysis. Nat Rev Microbiol 2008, 6(2):121-131.

6. Kong $Y$, Teather R, Forster R: Composition, spatial distribution, and diversity of the bacterial communities in the rumen of cows fed different forages. FEMS Microbiol Ecol 2010, 74:612-622.

7. Morelli L: Postnatal development of intestinal microflora as influenced by infant nutrition. J Nutr 2008, 138:1791S-1795S.

8. Harmsen HJ, Wildeboer-Veloo AC, Raangs GC, Wagendorp AA, Klijn N, Bindels $J G$, Welling GW: Analysis of intestinal flora development in breast-fed and formula-fed infants by using molecular identification and detection methods. J Pediatr Gastroenterol Nutr 2000, 30:61-67.

9. Fox PF: Indigenous enzymes in milk. In Advanced dairy chemistry-1 proteins. Edited by Fox PF. Springer US: McSweeney PLH; 2003:467-471.

10. Newburg DS: Oligosaccharides in human milk and bacterial colonization. J Pediatr Gastroenterol Nutr 2000, 30(Suppl 2):S8-S17.

11. Li R, Rock VJ, Grummer-Strawn L: Changes in public attitudes toward breastfeeding in the United States, 1999-2003. J Am Diet Assoc 2007, 107:122-127.

12. Jost R, Maire J-C, Maynard F, Secretin M-C: Aspects of whey protein usage in infant nutrition, a brief review. Int J Food Sci Technol 1999, 34:533-542.

13. Mace $K$, Steenhout $P$, Klassen $P$, Donnet $A$ : Protein quality and quantity in cow's milk-based formula for healthy term infants: past, present and future. Nestle Nutr Workshop Ser Paediatr Program 2006, 58:189-203.

14. Embleton ND, Cooke RJ: Protein requirements in preterm infants: effect of different levels of protein intake on growth and body composition. Pediatr Res 2005, 58:855-860.

15. Thureen $P$, Heird WC: Protein and energy requirements of the preterm/ low birthweight (LBW) infant. Pediatr Res 2005, 57:95R-98R.

16. Chatelais L, Jamin A, Gras-Le Guen C, Lalles JP, Le Huerou-Luron I, Boudry G: The level of protein in milk formula modifies ileal sensitivity to LPS later in life in a piglet model. PLoS One 2011, 6:e19594.

17. Hascoet JM, Hubert C, Rochat F, Legagneur H, Gaga S, Emady-Azar S, Steenhout PG: Effect of formula composition on the development of infant gut microbiota. J Pediatr Gastroenterol Nutr 2011, 52:756-762.

18. Oksanen J, Blanchet FG, Kindt R, Legendre P, Minchin PR, $O^{\prime} H$ Hara RB, Simpson GL, Solymos P, Stevens MH, Wagner H: Vegan: Community Ecology Package. R package version 2.0-5. 2012. http://CRAN.R-project. org/package=vegan .

19. Lonnerdal B: Nutritional and physiologic significance of human milk proteins. Am J Clin Nutr 2003, 77:1537S-1543S

20. Russell WR, Gratz SW, Duncan SH, Holtrop G, Ince J, Scobbie L, Duncan G, Johnstone AM, Lobley GE, Wallace RJ, Duthie GG, Flint HJ: High-protein, reduced-carbohydrate weight-loss diets promote metabolite profiles likely to be detrimental to colonic health. Am J Clin Nutr 2011, 93:1062-1072

21. Andriamihaja M, Davila AM, Eklou-Lawson M, Petit N, Delpal S, Allek F, Blais A, Delteil C, Tome D, Blachier F: Colon luminal content and epithelial cell morphology are markedly modified in rats fed with a high-protein diet. Am J Physiol Gastrointest Liver Physiol 2010, 299:G1030-G1037.

22. Nyangale EP, Mottram DS, Gibson GR: Gut microbial activity, implications for health and disease: the potential role of metabolite analysis. J Proteome Res 2012, 11(12):5573-5585. 
23. Kong XF, Wu GY, Liao YP, Hou ZP, Liu HJ, Yin FG, Li TJ, Huang RL, Zhang YM, Deng D, Kang P, Wang RX, Tang ZY, Yang CB, Deng ZY, Xiong H, Chu WY, Ruan Z, Xie MY, Yin YL: Effects of Chinese herbal ultra-fine powder as a dietary additive on growth performance, serum metabolites and intestinal health in early-weaned piglets. Livest Sci 2007, 108:272-275.

24. Heo JM, Kim JC, Hansen CF, Mullan BP, Hampson DJ, Pluske JR: Effects of feeding low protein diets to piglets on plasma urea nitrogen, faecal ammonia nitrogen, the incidence of diarrhoea and performance after weaning. Arch Anim Nutr 2008, 62:343-358.

25. Williams BA, Bosch MW, Awati A, Konstantinov SR, Smidt H, Akkermans ADL, Verstegen MWA, Tamminga S: In vitro assessment of gastrointestinal tract (GIT) fermentation in pigs: Fermentable substrates and microbial activity. Anim Res 2005, 54:191-201.

26. Lallès J-P, Bosi $P$, Smidt $H$, Stokes $C R$ : Weaning-A challenge to gut physiologists. Livest Sci 2007, 108:82-93.

27. Srinivasan M, Laychock SG, Hill DJ, Patel MS: Neonatal nutrition: metabolic programming of pancreatic islets and obesity. Exp Biol Med 2003, 228:15-23.

28. Srinivasan M, Song F, Aalinkeel R, Patel MS: Molecular adaptations in islets from neonatal rats reared artificially on a high carbohydrate milk formula. J Nutr Biochem 2001, 12:575-584.

29. Backhed F, Ley RE, Sonnenburg JL, Peterson DA, Gordon Jl: Host-bacterial mutualism in the human intestine. Science (New York, NY) 2005, 307:1915-1920.

30. Qin J, Li R, Raes J, Arumugam M, Burgdorf KS, Manichanh C, Nielsen T, Pons N, Levenez F, Yamada T, Mende DR, Li J, Xu J, Li S, Li D, Cao J, Wang B, Liang $H$, Zheng $H$, Xie $Y$, Tap J, Lepage P, Bertalan M, Batto JM, Hansen T, Le Paslier D, Linneberg A, Nielsen HB, Pelletier $E$, Renault $P$, et al: A human gut microbial gene catalogue established by metagenomic sequencing. Nature 2010, 464:59-65.

31. Claesson MJ, Cusack S, O'Sullivan O, Greene-Diniz R, de Weerd H, Flannery E, Marchesi JR, Falush D, Dinan T, Fitzgerald G, Stanton C, van Sinderen D, O'Connor M, Harnedy N, O'Connor K, Henry C, O'Mahony D, Fitzgerald AP, Shanahan F, Twomey C, Hill C, Ross RP, O'Toole PW: Composition, variability, and temporal stability of the intestinal microbiota of the elderly. Proc Natl Acad Sci U S A 2011, 108(Suppl 1):4586-4591.

32. Verschuere $L$, Rombaut $G$, Sorgeloos $P$, Verstraete W: Probiotic bacteria as biological control agents in aquaculture. Microbiol Mol Biol Rev 2000, 64:655-671.

33. Fernandez $\mathrm{L}$, Langa $\mathrm{S}$, Martin $\mathrm{V}$, Maldonado $\mathrm{A}$, Jimenez $\mathrm{E}$, Martin $\mathrm{R}$, Rodriguez JM: The human milk microbiota: origin and potential roles in health and disease. Pharmacol Res 2013, 69:1-10.

34. Sinkiewicz G, Ljunggren L: Occurrence of Lactobacillus reuteri in human breast milk. Microb Ecol Health Dis 2008, 20:122-126.

35. Ventura M, Canchaya C, Tauch A, Chandra G, Fitzgerald GF, Chater KF, van Sinderen D: Genomics of actinobacteria: tracing the evolutionary history of an ancient phylum. Microbiol Mol Biol Rev 2007, 71:495-548.

36. Benno Y, Sawada K, Mitsuoka T: The intestinal microflora of infants: composition of fecal flora in breast-fed and bottle-fed infants. Microbiol Immunol 1984, 28:975-986

37. Penders J, Thijs C, Vink C, Stelma FF, Snijders B, Kummeling I, van den Brandt PA, Stobberingh EE: Factors influencing the composition of the intestinal microbiota in early infancy. Pediatrics 2006, 118:511-521.

38. Palmer C, Bik EM, DiGiulio DB, Relman DA, Brown PO: Development of the human infant intestinal microbiota. PLOS Biol 2007, 5:e177.

39. Turnbaugh PJ, Hamady M, Yatsunenko T, Cantarel BL, Duncan A, Ley RE, Sogin ML, Jones WJ, Roe BA, Affourtit JP, Egholm M, Henrissat B, Heath AC, Knight R, Gordon Jl: A core gut microbiome in obese and lean twins. Nature 2009, 457:480-484

40. Schloss PD, Westcott SL, Ryabin T, Hall JR, Hartmann M, Hollister EB, Lesniewski RA, Oakley BB, Parks DH, Robinson CJ, Sahl JW, Stres B, Thallinger GG, Van Horn DJ, Weber CF: Introducing mothur: open-source, platform-independent, community-supported software for describing and comparing microbial communities. App/ Environ Microbiol 2009, 75:7537-7541.
41. Jami E, Israel A, Kotser A, Mizrahi I: Exploring the bovine rumen bacterial community from birth to adulthood. The ISME Journal 2013, 7:1069-1079.

42. Fouts DE, Szpakowski S, Purushe J, Torralba M, Waterman RC, MacNeil MD, Alexander LJ, Nelson KE: Next generation sequencing to define prokaryotic and fungal diversity in the bovine rumen. PloS one 2011, 7:e48289.

doi:10.1186/s12866-014-0279-2

Cite this article as: Fan et al:: Infant formula supplemented with low protein and high carbohydrate alters the intestinal microbiota in neonatal SD rats. BMC Microbiology 2014 14:279.

\section{Submit your next manuscript to BioMed Central and take full advantage of:}

- Convenient online submission

- Thorough peer review

- No space constraints or color figure charges

- Immediate publication on acceptance

- Inclusion in PubMed, CAS, Scopus and Google Scholar

- Research which is freely available for redistribution

Submit your manuscript at www.biomedcentral.com/submit
C) BioMed Central 